\title{
EFFECTIVENESS OF INSECTICIDES ROTATION WITH DIFFERENT MODES OF ACTION AGAINST OIL PALM BUNCH MOTH Tirathaba mundella (WALKER) (Lepidoptera, Pyralidae)
}

\author{
SU CHONG MING ${ }^{1}$, PATRICIA KING JIE HUNG ${ }^{1,2^{*}}$, KWAN YEE MIN ${ }^{1}$, \\ ZAKRY FITRI AB AZIZ ${ }^{1,2}$ and ONG KIAN HUAT ${ }^{1}$ \\ ${ }^{1}$ Faculty of Agricultural Science and Forestry, Universiti Putra Malaysia, \\ Bintulu Sarawak Campus \\ ${ }^{2}$ Institut Ekosains Borneo, Universiti Putra Malaysia, \\ Bintulu Sarawak Campus \\ *E-mail: patricia@upm.edu.my
}

Accepted 18 May 2021, Published online 30 May 2021

\begin{abstract}
Tirathaba mundella Walker has emerged as one of the most prominent bunch feeding pests in Sarawak peat oil palm estates. Insecticides application is inevitable to prevent economic loss. However, to protect insect pollinators which cohabitat with the pest and reduce the risk of resistance development among the pest to insecticides, rotation treatments with more than one pollinator-friendly insecticides is recommended. This paper examines the effectiveness of rotating several pollinator-friendly insecticides in controlling the pest. To assess the effectiveness of different rotation combination, a field study on a seven-year-old peat estate was carried out using several insecticides combinations and application intervals, then the level of infestation post-treatment was assessed. Significantly, the results showed that only four single rounds of insecticides application in a year would yield relatively better control than nine rounds of Bacillus thuringiensis applications. Overall, there was no significant difference in clean bunches percentages obtained between five rounds of treatment compared to only four rounds per year. The result strengthens our confidence that the optimum and most cost-effective approach for one-year protection against $T$. mundella was two rounds of $30.0 \mathrm{~g}$ active ingredient of chlorantraniliprole per ha rotated with two rounds of $25.0 \mathrm{~g}$ active ingredient of chromafenozide. The material cost was calculated as RM 351.20 per ha per year. The findings of this study would benefit future pest management practice in oil palm plantation established on peatland.
\end{abstract}

Key words: Bunch moth, chlorantraniliprole, oil palm, Tirathaba mundella

\section{INTRODUCTION}

Out of the total 554,775 ha of peatland that is developed into agricultural land, $56.60 \%$ has been converted into oil palm cultivation (Paramananthan, 2016). With such a large area converted from heterogeneous climatic climax vegetation into mono species crop for oil palm since the year 2005 and much more rapidly in late 2008 had indirectly upset the natural biological balances between hosts, pests and natural enemies of pests, which have achieved equilibrium over the millennia. The oil palm bunch moth, Tirathaba mundella Walker, among others (i.e. termites, rhinoceros beetles, nettle caterpillars, bagworms and rats) is one of the most important and problematic pests in young mature oil palms planted

* To whom correspondence should be addressed. in peat. The larvae of $T$. mundella feed on the oil palm inflorescences (Wood \& $\mathrm{Ng}, 1974$ ) and able to bore through oil palm fruitlets to gain access to the juicy embryo-containing kernel ( $\mathrm{Su}$ et al., 2016). When T. mundella infestation exceeds the economic injury level as determined in $\mathrm{Su}$ et al. (2020), a significant economic loss could result from a substantial number of young fruit bunches falling prematurely or developing a hollow centre instead of a kernel, leading to a condition known as bunch abortion.

The amount of published information on the effect of chemical insecticides against oil palm bunch moth in oil palm plantation has been scant (Su, 2016). Mohd et al. (1991) evaluated insecticides and cultural practice as control measures on oil palm bunch moth in a mature oil palm plantation at Teluk Intan, and since then, no further studies have been conducted 
on this particular pest until recent years. Su (2016) reported that two insecticides that share a similar mode of action against Lepidoptera, namely chlorantraniliprole and flubendiamide, both have excellent control on this pest in four to five months when sprayed at fortnightly intervals. Similar results on the effectiveness of chlorantraniliprole against oil palm bunch moth were also reported by the Malaysian Palm Oil Board where it was proven to have longer effects in reducing bunch moth population which lasted more than 50 days after the last round of spraying, without affecting the natural population of oil palm pollinators that co-existed in the oil palm plantation (Saharul et al., 2017).

At present, planters from the oil palm industry still widely adopt Bacillus thuringiensis-based pesticides as their main approach of controlling oil palm bunch moth. Being a pesticide that is easily inactivated by ultraviolet light, more than six rounds of application are required annually to give fair protection against oil palm bunch moths. This control practice is regarded as economic infeasible especially when the price of crude palm oil is low. Moreover, the practice is very labour intensive and become impractical in the current situation when an acute shortage of workforce is a norm. Therefore, oil palm planters are looking for more efficient control measures to curb the oil palm bunch moth infestation.

In this study, a field trial was initiated to test the effectiveness of rotating insecticides of different modes of action against oil palm bunch moth, T. mundella in young mature oil palm plantation. Rotating the use of different insecticides against T. mundella could potentially reduce the frequency of application, which would make it more practical and economically feasible; whilst lowering the risk of the pest developing insecticide resistance.

\section{MATERIALS AND METHODS}

A field study was carried out at a young yet mature seven-year-old oil palm estate planted on peat. The design of the experiment was a complete randomised block design with four replicates and each replicate consisted of four rows of palms with eleven palms in each planting row. A total of 22 palms were selected as sampling palms for each treatment. The size of the trial plot was 8.75 ha.

Seven rotation regimes were selected to test their effectiveness in controlling $T$. mundella. B. thuringiensis 17,600 IU/mg, the common insecticide used in oil palm estates to control insect pest was used as a control to serve as a benchmark against other insecticide application regimes. The other insecticides tested in this study were Altacor $(34.9 \%$ w/w chlorantraniliprole), Symphony $(45.5 \% \mathrm{w} / \mathrm{w}$ pyridalyl), Matric (4.9\% w/w chromafenozide) and Cascade $(5.3 \% \mathrm{w} / \mathrm{w}$ flufenoxuron). The different application intervals of insecticides adopted in this trial were based on the initial results obtained ( $\mathrm{Su}$, 2016). From the results of the study, it was noted that biological insecticide, Bt, with back-to-back double rounds of application at 14 days interval only offered protection against $T$. mundella for three months. On the other hand, one round of chlorantraniliprole application could last for four months (16 weeks) while for other chemical insecticides, namely pyridalyl and flufenoxuron, a single round of application could last for three months (12 weeks). Based on these results, the spray rotation that involved different insecticides and intervals for this trial was designed to cover one-year protection against the pest in the field. The dosing used per hectare and the rotation regime are tabulated in Table 1 and Table 2.

Table 1. Insecticide application dose used per hectare

\begin{tabular}{lcc}
\hline Treatment & $\begin{array}{c}\text { Product dose } \\
\text { per ha }\end{array}$ & $\begin{array}{c}\text { a.i. of product } \\
\text { per ha }\end{array}$ \\
\hline Bacillus thuringiensis 17,600 I.U/mg (T1) & $600 \mathrm{~mL}$ & $6.6 \times 10^{6} \mathrm{I.U}$ \\
Chlorantraniliprole 34.9\% w/w rotated with Bacillus thuringiensis & $85 \mathrm{~g}$ & $30.0 \mathrm{~g}$ \\
17,600 I.U/mg(T2) & $600 \mathrm{~mL}$ & $6.6 \times 10^{6} \mathrm{I.U}$ \\
Chlorantraniliprole 34.9\% w/w rotated with Flufenoxuron 5.3\% w/w (T3) & $85 \mathrm{~g} 70 \mathrm{~mL}$ & $30.0 \mathrm{~g} 37.0 \mathrm{~g}$ \\
Chlorantraniliprole 34.9\% w/w rotated with Flufenoxuron 5.3\% w/w (T4) & $85 \mathrm{~g} 700 \mathrm{~mL}$ & $30.0 \mathrm{~g} 37.0 \mathrm{~g}$ \\
Chlorantraniliprole 34.9\% w/w rotated with Chromafenozide 4.9\% w/w (T5) & $85 \mathrm{~g} 500 \mathrm{~mL}$ & $30.0 \mathrm{~g} 25.0 \mathrm{~g}$ \\
Chlorantraniliprole 34.9\% w/w rotated with Pyridalyl 45.5\% w/w (T6) & $85 \mathrm{~g} 180 \mathrm{~mL}$ & $30 \mathrm{~g} 82.0 \mathrm{~g}$ \\
Chlorantraniliprole 34.9\% w/w rotated with Bacillus thuringiensis & $85 \mathrm{~g}$ & $30.0 \mathrm{~g}$ \\
17,600 I.U/mg and Chromafenozide 4.9\% w/w (T7) & $600 \mathrm{~mL}$ & $6.6 \times 10^{6} \mathrm{I.U}$ \\
& $500 \mathrm{~mL}$ & $25.0 \mathrm{~g}$ \\
\hline
\end{tabular}

a. $\mathrm{i}=$ active ingredient 


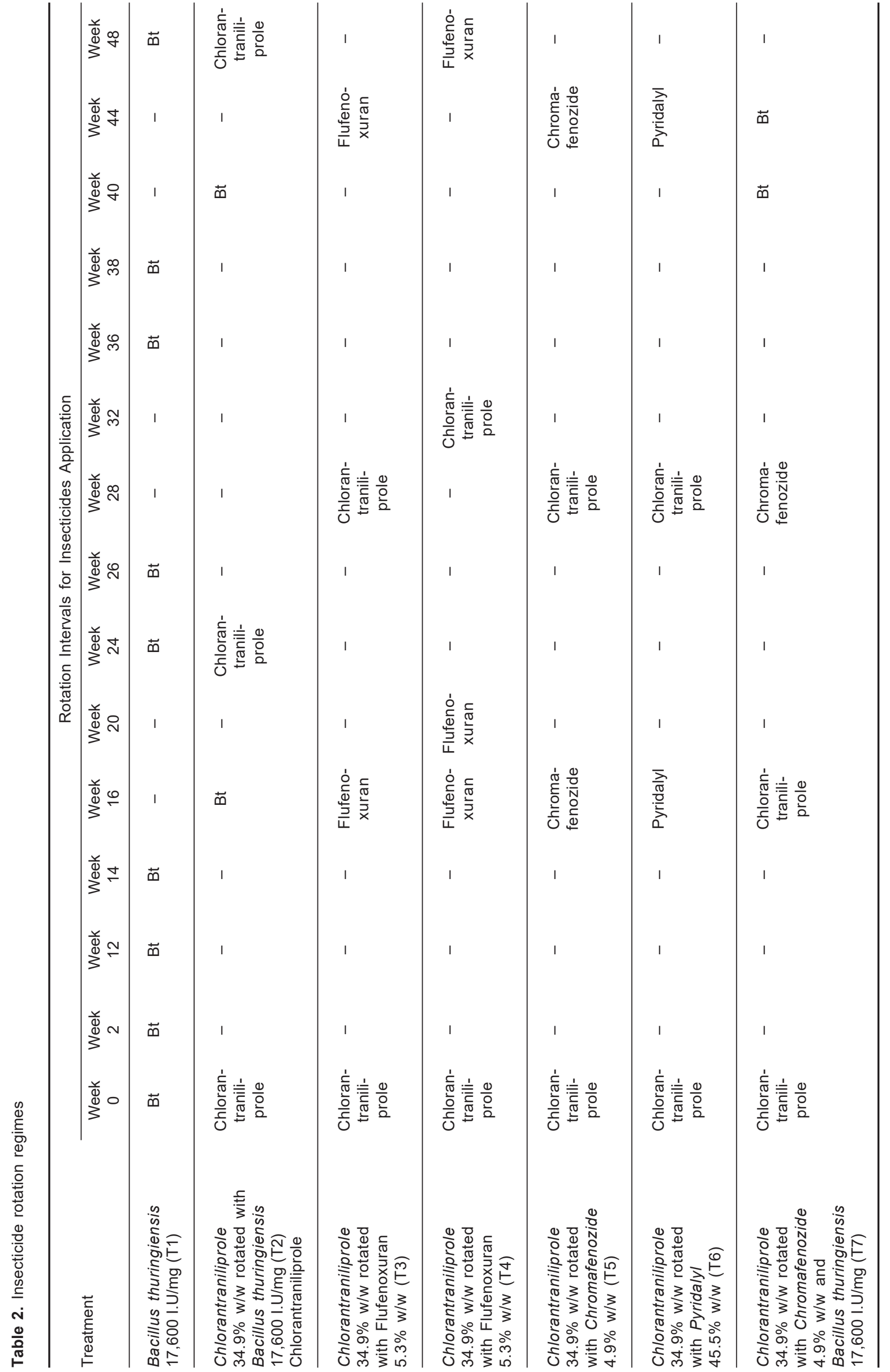


The insecticide application in the field was accomplished manually using a PB-16 knapsack sprayer attached with an LSA4 solid cone nozzle. One litre of insecticide mixture solution was delivered to each palm to thoroughly wet the oil palm fruit bunches and male inflorescences present on the palm with a spray volume of $150 \mathrm{~L}$ per ha.

Before the commencement of the first-round insecticide spraying, that is week 0 , a baseline field census was carried out and this was followed by a monthly census after the treatment for twelve consecutive months. The main objective of conducting a census at a monthly interval is to closely monitor the pests' infestation level so a subsequent insecticide application could be carried out before $T$. mundella density reached the economic injury level (Su et al., 2020).

During the census, all bunches present on the palms in the study areas were examined and the severity of oil palm bunch moth infestation was recorded. The severity of pest infestation was determined based on the detailed criterion in $\mathrm{Su}$ et al. (2020). The bunches were categorised into three groups based on their infestation severity stages, namely clean-to-lightly infested, moderately infested, and severely infested. The clean-to-lightly infested category characterised fruit bunches that did not show any obvious sign of infestation or had less than $25 \%$ of the surface covered with pest frass. Moderate infestation referred to a condition where more than $25 \%$ but less than $50 \%$ of the surface was covered with pest frass while severe infestation referred to a condition where more than $50 \%$ of the surface was covered by the frass.

The monthly field census data of T. mundella consist of binomial data expressed in percentage terms, the analysis of such enumeration data is best accomplished by first taking square-root transformation for each observation before proceeding with the analysis of variance (ANOVA) using the statistical analysis system (SAS) version 8.2 (SAS Institute Inc., Cary, NC, USA). The mean percentage of infestation is separated using the Duncan New Multiple Range test at a significant level of $p=0.05$.

\section{RESULTS}

For the mean percentages of clean-to-lightly infested fruit bunches, there was no significant difference between all the treatments at week 0 , with the range of $11 \%$ to $27 \%$ (Figure 1). Throughout the 52-week monitoring period after insecticides applications, the mean percentages of moderately infested fruit bunches in all the treatments fluctuate around $15 \%$ to $25 \%$. There was no significant difference in the mean percentages of moderately infested bunches for all the treatments from week 0 to week 12, week 24, and week 36 to week 48 (Figure $2 \& 3$ ). Since there was no obvious trend that could be observed for the mean percentage of moderately infested fruit bunches

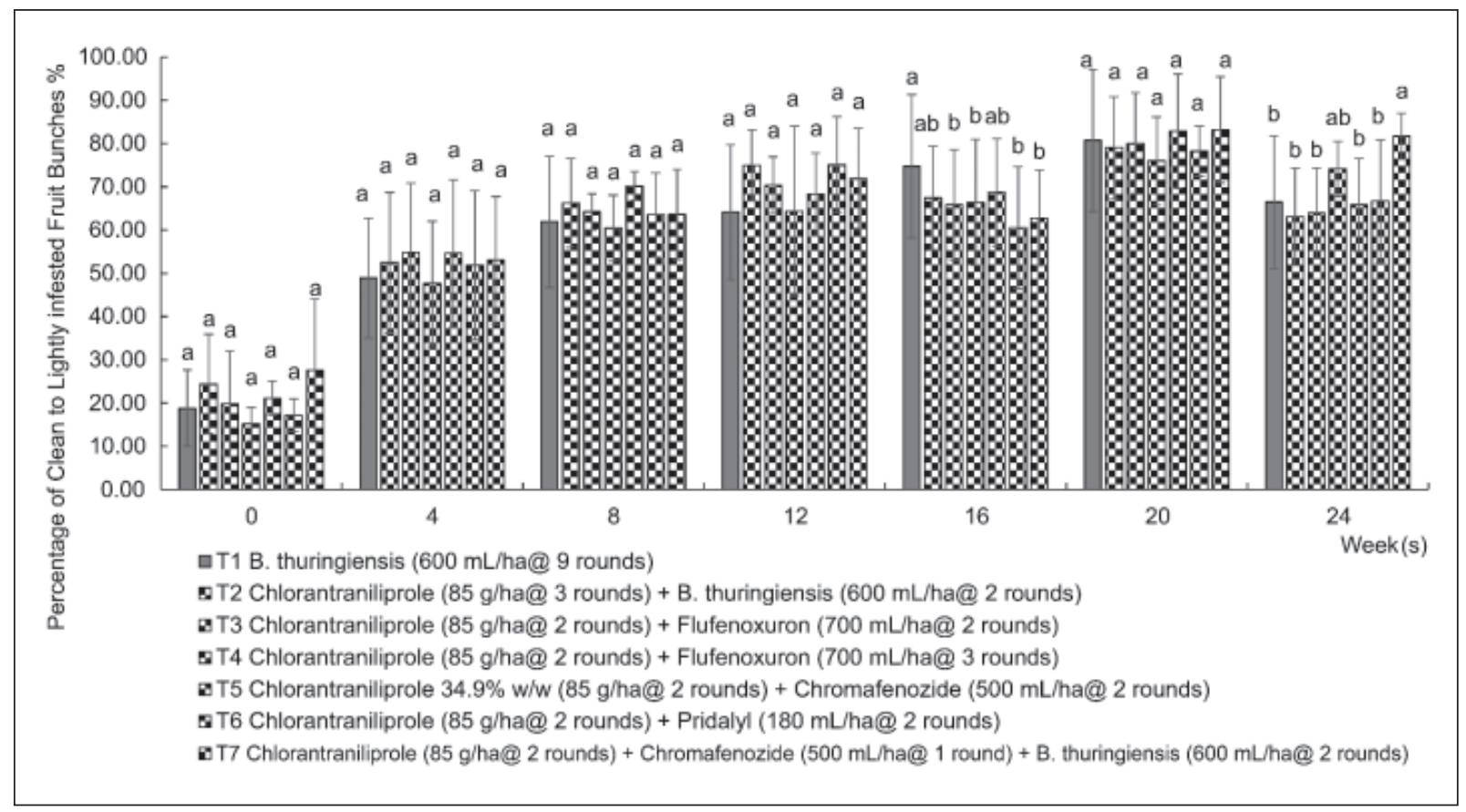

Fig. 1. Mean percentage of clean to lightly infested fruit bunches in insecticides treated fields from week 0 to week 24 . Means with the same letters within the sampling period are not significantly different according to Duncan's Multiple Range Test, $(p=0.05)$. The vertical bars represent the standard error of means for 4 replicates. 


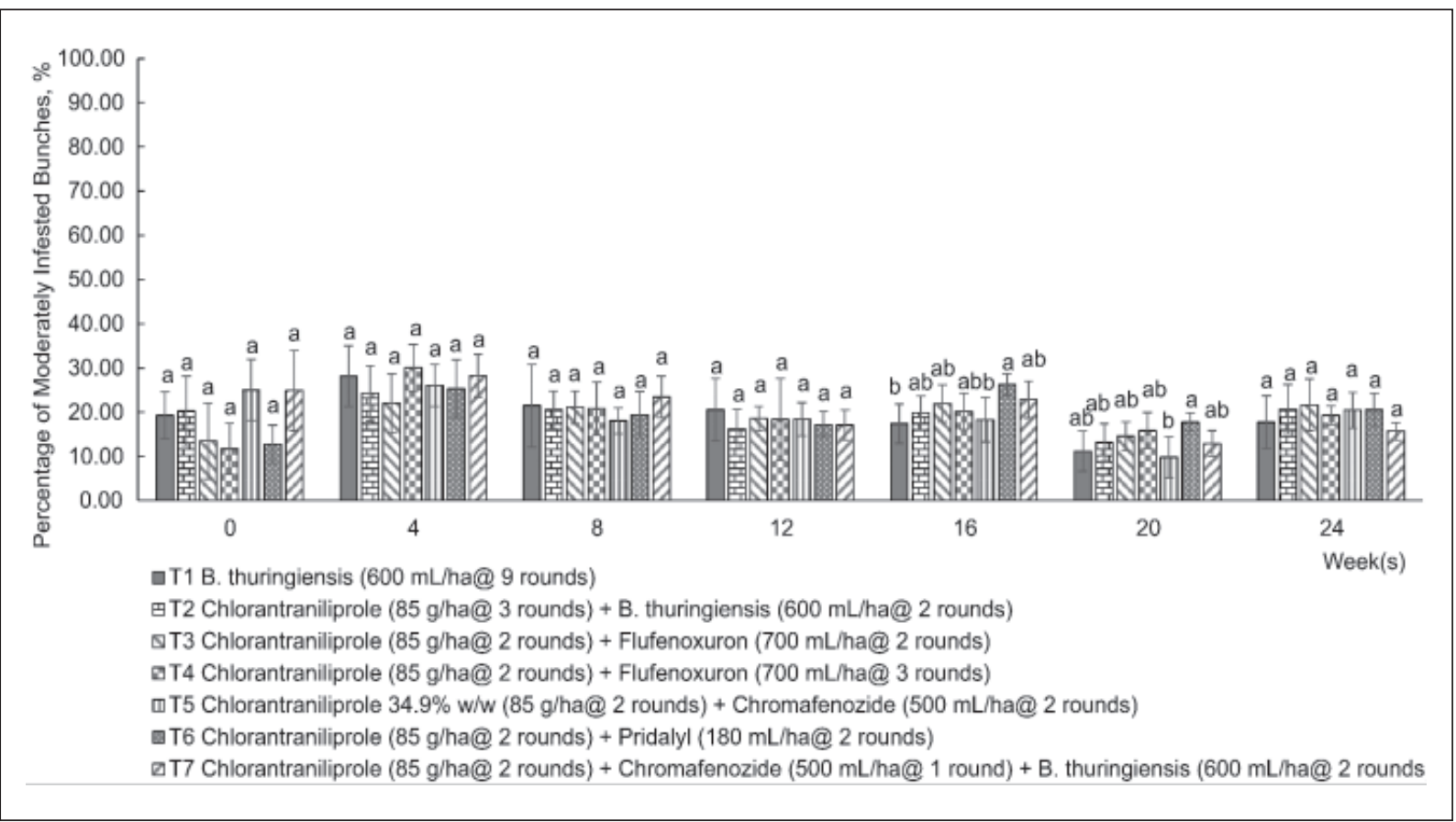

Fig. 2. Mean percentage of moderately infested fruit bunches in insecticides treated fields from week 0 to week 24 . Means with the same letters within the sampling period are not significantly different according to Duncan's Multiple Range Test, $(p=0.05)$. The vertical bars represent the standard error of means for 4 replicates.

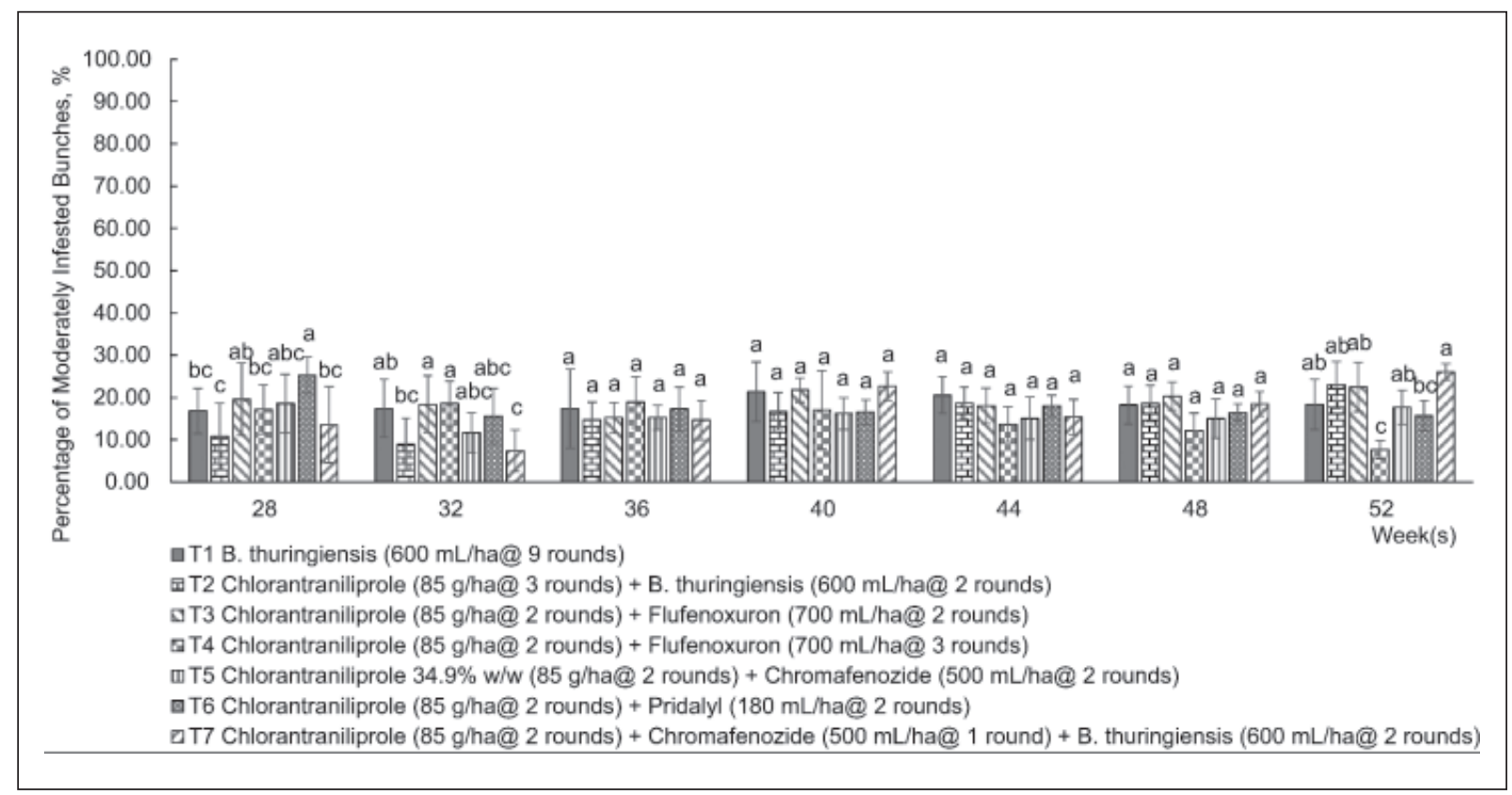

Fig. 3. Mean percentage of moderately infested fruit bunches in insecticides treated fields from week 28 to week 52 . Means with the same letters within the sampling period are not significantly different according to Duncan's Multiple Range Test, $(p=0.05)$. The vertical bars represent the standard error of means for 4 replicates.

in all those treatment plots throughout the one-year monitoring period, the moderately infested fruit bunches are therefore considered as not a good field assessment parameter to gauge the effectiveness of the insecticides applied. The mean percentage of clean-to-lightly infested fruit bunches corresponds negatively to severely infested fruit bunches. Therefore, both can serve as good indicators for pest infestation level.

One month after insecticides application, the mean percentage of severely infested fruit bunches in all the treatment plots dropped substantially, 
ranging from $18 \%$ to $23 \%$ (Figure 4 ). There was no significant difference in the mean percentage of severely infested fruit bunches among all the treatments between week-4 to week-12.

In the control (Treatment 1), a total of nine rounds $B$. thuringiensis at $600 \mathrm{~mL}$ per ha was applied in a year. The mean percentage of clean-to-lightly infested fruit bunches increased from $18.79 \%$ in week 0 to $62 \%$ in week 8 and further increased to $80 \%$ in week 20 after four rounds of B. thuringiensis exercised. It was also noted that Treatment 1 was as effective as the other treatments in protecting palms against $T$. mundella for the first five months. However, six weeks after the eighth application of $B$. thuringiensis, the mean percentage of clean-to-lightly infested fruit bunches plunged below 60\% (Figure 5). Overall results of Treatment 1 revealed that the mean percentages of clean bunches were inconsistent and fluctuate around $50 \%$ to $60 \%$ throughout the monitoring period.

Interestingly, two rounds of B. thuringiensis applied after three rounds of chlorantraniliprole (Treatment 2) provided a comparable pest control effect as compared to nine rounds of B. thuringiensis alone in a year. A similar effect was observed in Treatment 7 where two rounds of chlorantraniliprole and one round of chromafenozide were applied before two rounds of $B$. thuringiensis. This showed that working with chemical insecticides could reduce the number of $B$. thuringiensis application per year to offer a similar pest control effect.

Compared to $B$. thuringiensis, chemical insecticides performed better as observed in Treatment 4 and Treatment 5. Both Treatment 4 and Treatment 5 had higher occurrences of clean fruit bunches, meaning lower occurrences of severely infested fruit bunches after insecticides application. Moreover, both Treatment 4 and Treatment 5 only required between four and five pesticides applications in a year, which were two rounds of chlorantraniliprole, followed by three rounds flufenoxuron in $\mathrm{T} 4$; and two rounds of chlorantraniliprole and two round of chromafenozide in T5. This greatly reduces labour cost expressed in terms of man-hour which is an essential advantage considering the current status of acute labour shortage faced by many oil palm plantation companies, especially in the Sarawak region.

It is important to note that based on one-year monitoring results (Table 3 ), there was no significant advantage in five rounds of chemical treatment (Treatment 4) over only four rounds per year as demonstrated in Treatment 5. Taking into consideration of the material cost (Table 4), Treatment 5 which costed RM 351.20 per ha per year, appeared to be the most reliable, practical and cost-effective control method for oil palm bunch moth on peat.

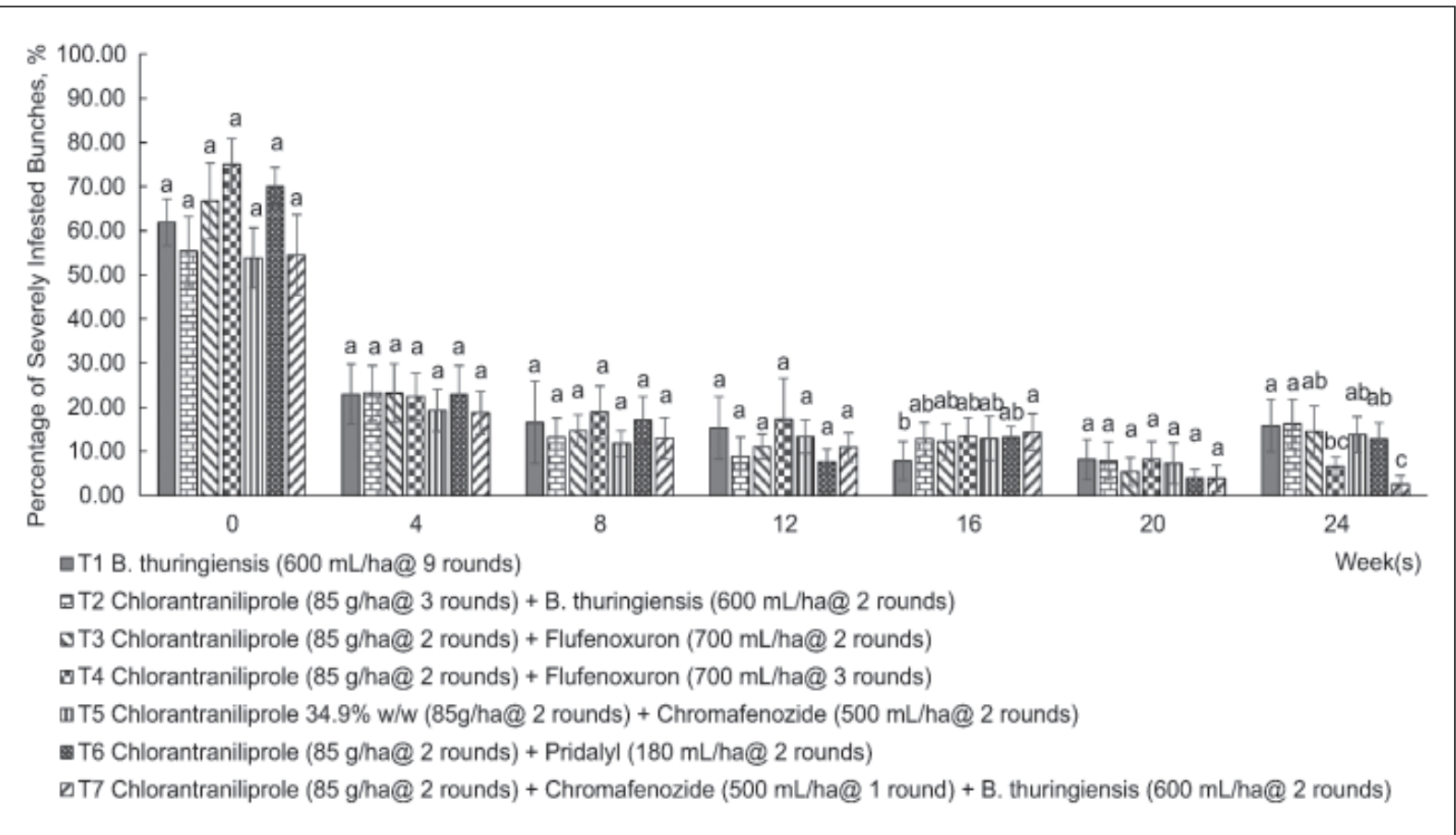

Fig. 4. Mean percentage of severely infested fruit bunches in insecticide-treated fields from week 0 to week 24 . Means with the same letters within the sampling period are not significantly different according to Duncan's Multiple Range Test, $(p=0.05)$. The vertical bars represent the standard error of means for 4 replicates. 


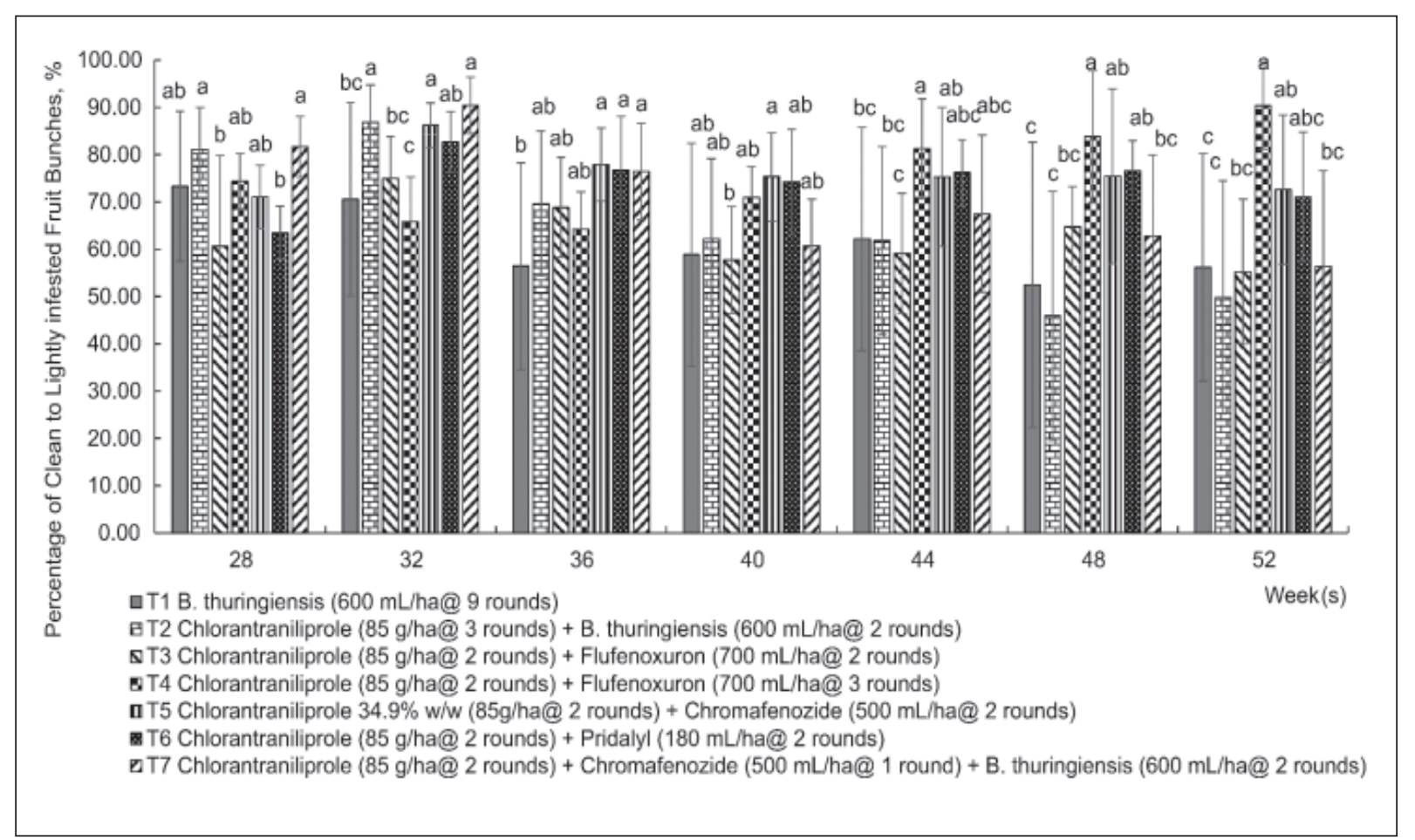

Fig. 5. Mean percentage of clean to lightly infested fruit bunches in insecticides treated fields from week 28 to week 52 . Means with the same letters within the sampling period are not significantly different according to Duncan's Multiple Range Test, $(p=0.05)$. The vertical bars represent the standard error of means for 4 replicates.

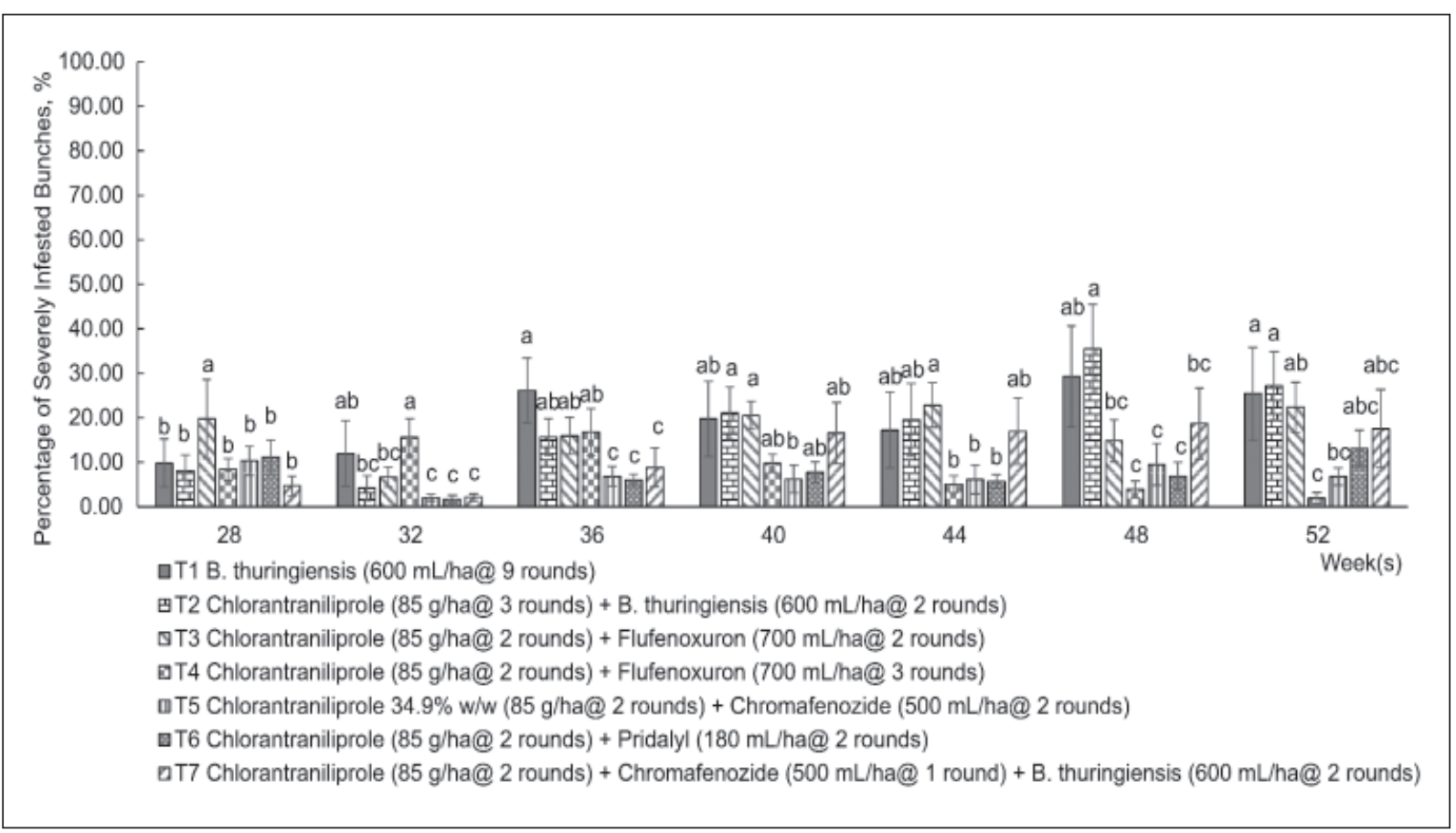

Fig. 6. Mean percentage of severely infested fruit bunches in insecticides treated fields from week 28 to week 52 . Means with the same letters within the sampling period are not significantly different according to Duncan's Multiple Range Test, $(p=0.05)$. The vertical bars represent the standard error of means for 4 replicate. 

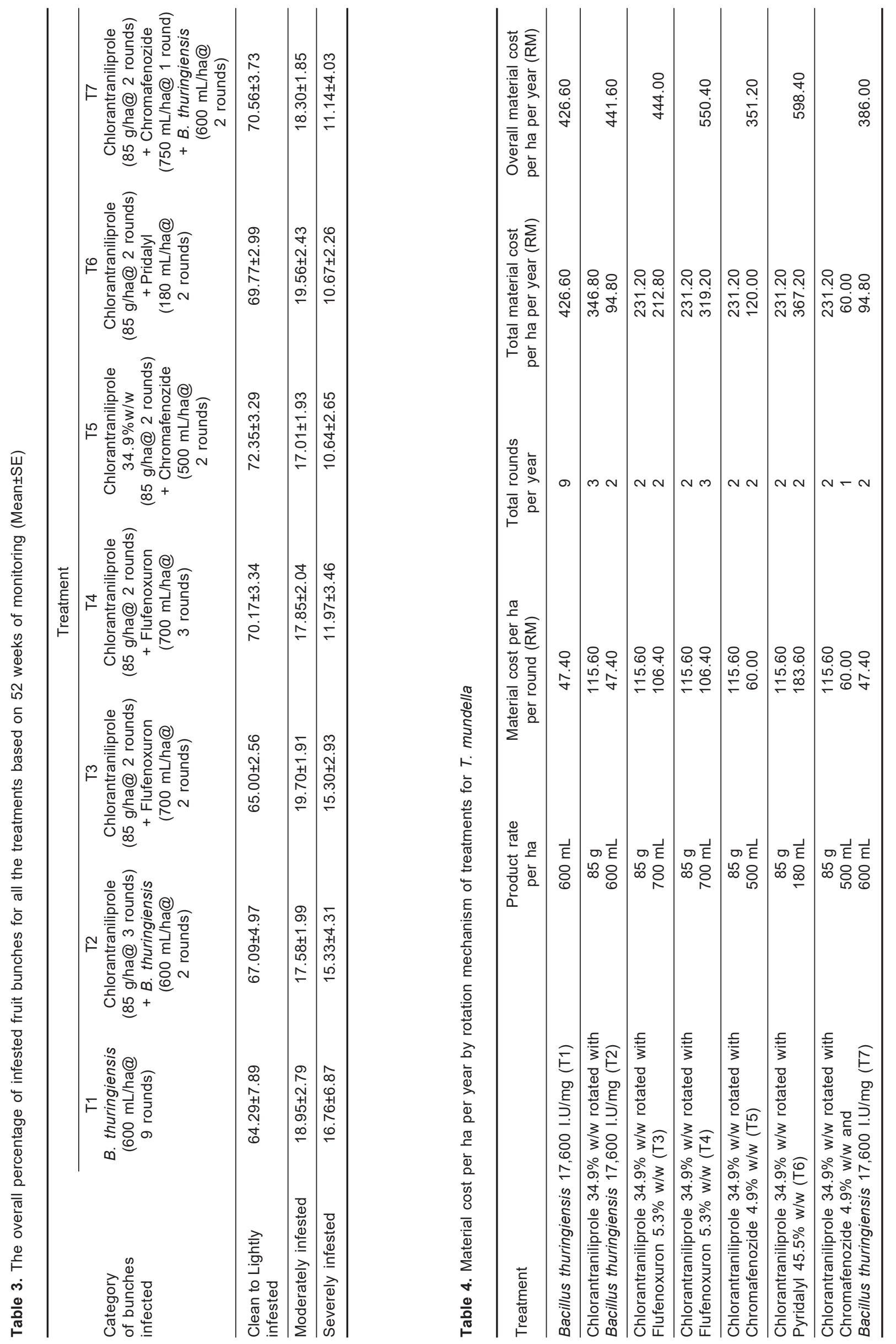


\section{DISCUSSION}

Throughout the one year monitoring period, it was noted that even though a maximum of nine rounds B. thuringiensis (Treatment 1) was exercised, which estate management would have difficulties coping with, mainly due to an acute labour shortage faced by the industry, the maximum mean percentage of clean-to-lightly infested fruit bunches obtained would only hover around $50 \%$ to $60 \%$ which is not as good when compared to chemical treatment that would yield more than $75 \%$ clean-to-lightly infested fruit bunches at the end of 52-week monitoring period with only four rounds of chemical treatment in a year. The limitation of the biological insecticide means that the active ingredient of $B$. thuringiensis insecticide must be ingested by the target pest to be effective, and it has a short shelf life in the field due to direct exposure to ultraviolet radiation from the Sun. The efficacy of $B$. thuringiensis in controlling pest is affected by several factors such as sunlight, temperature, pest density and the presence of associated filter-feeding non-target organisms (Dunkle \& Shasha, 1989). Out of which, solar inactivation of $B$. thuringiensis and other entomopathogens is a widely recognised phenomenon. It is commonly known that sunlight is composed of UV-B with wavelengths between 290-320 nm, UV-A between 320-390 nm, the visible length between $390-780 \mathrm{~nm}$ and infrared radiation which is longer than $780 \mathrm{~nm}$ (Saxena et al., 2010). The high-energy photons of ultraviolet radiation harm cells by directly damaging the pyrimidine dimers, cross-linking with proteins or by producing reactive oxygen-derived free radicals (Saxena et al., 2010). The half-life for $B$. thuringiensis has been estimated at 3.8 hours when exposed to an ultraviolet source equivalent to the ultraviolet radiation in natural sunlight (Ignoffo et al., 1977). Therefore, precautionary measures on methodology and timing of application would be necessary when applying $B$. thuringiensis in the fields to maximise the potentials of the biological insecticide which is a moot concern in the sense of practicality for estate operation given the current state of affairs.

Despite having the advantages of posing no harmful effects on vertebrates, humans and even the ecological environment, the relatively short field life span of the spray of this bioinsecticide would limit the usefulness of $B$. thuringiensis in controlling pest such as T. mundella.

Both Treatment 4 and Treatment 5 showed a good pest controlling effect against $T$. mundella. In both treatments, chlorantraniliprole was applied in week 0 . Chlorantraniliprole is a ryanodine receptor modulator insecticide that selectively targets the insect ryanodine receptors that regulate the flow of calcium. The binding of the active ingredient of the chlorantraniliprole to the receptor stimulates the uncontrolled release of calcium from the internal stores of smooth and striated insect muscle (Carl et al., 2017; Axel et al., 2009; Mahdieh et al., 2017) and impairs muscle regulation, causes rapid muscle dysfunction of the target insect, which leads to paralysis and ultimately death of the insect (Lahm et al., 2007; Lessando et al., 2015). This mode of action has no cross-resistance with other conventional insecticidal modes of action (Andrea et al., 2009). This makes chlorantraniliprole a suitable rotational insecticide in controlling pests in oil palm plantations.

Chlorantraniliprole also demonstrates significant residual activity. It can travel via absorption and upward translocation by xylem to new leaves (Pes et al., 2020). This would allow chlorantraniliprole to linger on, released, and translocated to other parts of the plant as conditions in the plant change (Logan, 1974). This makes chlorantraniliprole a systemic insecticide that has a considerable long residual effect. On top of that, chlorantraniliprole shows resistance to photo-degradation as well as posting reasonably well rainfastness criteria when applied to a target crop (Temple et al., 2009; Gustavo et al., 2015). Besides that, chlorantraniliprole has also been designated as a reduced-risk insecticide by the United States Environmental Protection Agency, for it has very low toxicity to bees and most types of predatory and parasitic insects that contribute to pest suppression (Carl et al., 2017). The insecticides used to protect oil palm fruit bunches in a plantation setting need to have consistent efficacy against targeted insect pest across different field conditions, low mammalian toxicity, minimal impact on naturally available pollinators, and chlorantraniliprole meets these criteria ( $\mathrm{Su}, 2016)$.

With this advantage, two successive rounds of chlorantraniliprole rotated with another two or three rounds of other chemical insecticides namely pyridalyl, chromafenozide or flufenoxuron provided sufficient protection coverage for 12 months against T. mundella (Table 3). With only four-to-five rounds of pesticides application, the labour cost can be reduced and made more feasible in the current working environment where acute labour shortage is a norm. The insecticide-rotation strategy of applyingchlorantraniliprole and the other chemical insecticides with different modes of action may also slow down the build-up of resistance among the pest, which indirectly contributes to the sustainability of the insecticide consumption, integrated pest management and pest resistant management.

Flufenoxuron, 1-[4-(2-chloro- $\alpha, \alpha, \alpha$-trifluoro-ptolyloxy)-2-fluorophenyl]-3-(2,6-difluorobenzoyl) is an insect growth regulator insecticide that belongs to the chemical class of benzoylurea and it prevents the formation of chitin, which is the vital component of insect cuticle (Manogem et al., 2015). Insect 
growth regulators insecticides act directly on the immature stages of both nymphs and larvae for most lepidopteran pests and adults of certain insect pests. Flufenoxuron could also affect the hormonal balance in target insects resulting in physiological disturbances such as inhibition of deoxyribonucleic acid synthesis, alteration of carbohydrates, increase in phenyloxidase activity, microsomal oxidase and cuticular lipids. On exposure to flufenoxuron, target insect larvae would die at the next moulting stage or during the ensuing instar. While flufenoxuron is an insect growth regulator, it has low gross toxicity to non-target organisms like parasitoids, pollinators and other beneficial insects in as much as chemical insecticides do. This warrants flufenoxuron as a potential alternative insecticide to control oil palm bunch moth which exerts low impact on oil palm natural pollinators that coexist in the oil palm plantation.

In Treatment 5, Chlorantraniliprole $34.9 \% \mathrm{w} / \mathrm{w}$ was rotated with $4.9 \% \mathrm{w} / \mathrm{w}$ chromafenozide, 3,4dihydro-5-methyl-2H-1-benzopyran-6-carboxylic acid 2-(3,5- dimethylbenzoyl)-2-(1,1-dimethylethyl) hydrazide and showed higher clean fruit bunches and lower severely infested fruit bunches after insecticides application as compared to Bt pesticide. Moreover, Treatment 5 also needed only four applications per year to provide satisfactory protection against $T$. mundella, which makes Treatment 5 an excellent choice in oil palm bunch moth management. Chromafenozide has high lepidopteran specificity that interfered with the targeted insect moulting process (Ahmed et al., 2015; Saleh \& Abdel-Gawad, 2018). Chromafenozide would bind onto the ecdysteroid receptor complex of the insect and disrupt the genes expression involved in the moulting process (Hadi et al., 2008; Arthur et al., 2003).

The findings of this study showed that comparing the percentage of moderately infested fruit bunches did not yield significant differences across all treatments throughout the 52 weeks of monitoring. Moderately infested fruit bunches could result in an eight per cent loss in oil extraction rate (Su et al., 2020), however, it did not serve as a good parameter in determining the effectiveness of an insecticide. The percentage of clean-to-lightly infested or severely infested bunches was found to be more prominently indicating the pest control effectiveness.

There is a considerable amount of literature reporting that using pesticides with the same modes of action could contribute to the development of pesticide resistance in the target pest. Therefore, rotating different pesticides with various mechanisms is a useful strategy to avoid or slow down insecticide resistance problems (Ghoneim et al., 2012). This study has shown that chromafenozide rotated with chlorantraniliprole (Treatment 5) is effective in controlling oil palm bunch moth, T. mundella. This rotation regime required only four rounds of application to maintain clean bunches above $70 \%$ with a calculated material cost of RM 351.20 per ha per year (Table 4). The overall performance of Treatment 5 is considered to be the most reliable treatment option in terms of effectiveness, practicality and economical perspective.

\section{CONCLUSION}

From the mean percentages of clean-to-lightly infested fruit bunches and severely infested fruit bunches discussed above, it is clear that for an area with endemic T. mundella outbreak, proper utilisation of appropriate chemical insecticides to suppress the pest population is of utmost importance to reduce the economic losses in a long-term perspective. The results of this study suggest that the deployment of insecticide rotation programs with different modes of action would improve the overall performance of pest control under actual field conditions. This would also lead to a more potent use of toxicants which could theoretically prevent or delay the emergence of resistant strains of $T$. mundella Walker within a short period, in addition to reducing the frequency of spraying and consequently cutting down labour cost as well as environmental pollution. Treatment 5 with two rounds of chlorantraniliprole rotated with two rounds of chromafenozide carries a high potential to be adopted as one of the most costeffective, practical and sustainable approaches for controlling oil palm bunch moth, T. mundella Walker under a large scale commercial spraying typical in oil palm plantations planted on peat.

\section{REFERENCES}

Ahmed, K.S., El-Bermawy, S.M., Ismael, E.H., AbdelGawwad, R.M. \& Saleh, T.A. 2015. Histopathological effects of diflubenzuron and chromafenozide (IGRs) on egg development in the cotton leafworm Spodoptera littoralis (Boisd.) (Lepidoptera, Noctuidae). Journal of Bioscience and Applied Research, 1(4): 147-153.

Andrea, B., Rison, J.L. \& Wiles, J.A. 2009. Chlorantraniliprole (DPX-EZY45, Rynaxypyr ${ }^{\circledR}$, Coragen ${ }^{\circledR}$ ), a new diamide insecticide for control of codling moth (Cydia pomonella), Colorado potato beetle (Leptinotarsa decemlineata) and European grapevine moth (Lobesia botrana), in: Proceedings of the 9th Slovenian Conference on Plant Protection. Plant Protection Society of Slovenia, Nova Gorica, pp. 4-5. 
Arthur, R., Krell, P., Feng, Q. \& Arif, B. 2003. Ecdysone agonists: Mechanism and importance in controlling insect pests of agriculture and forestry. Archives of Insect Biochemistry and Physiology, 54: 187-199.

Axel, D., Kristin, E.B., Niels, M.F. \& Michael, D.W. 2009. Chlorantraniliprole (Rynaxypyr): A novel DuPont ${ }^{\mathrm{TM}}$ insecticide with low toxicity and low risk for honeybees (Apis mellifera) and bumblebees (Bombas terrestris) providing excellent tools for uses in integrated pest management, in: Proceedings from $10^{\text {th }}$ International Symposium of the ICP-Bee Protection Group, Bucharest, pp. 548-555.

Carl, T.R. \& Daniel, A.P. 2017. Chlorantraniliprole: Reduced-risk insecticide for controlling insect pests of woody ornamentals with low hazard to bees. Journal of Arboriculture \& Urban Forestry, 43(6): 242-256.

Dunkle, R.L. \& Shasha, B.S. 1989. Response of starch-encapsulated Bacillus thuringiensis containing ultraviolet screens to sunlight. Environmental Entomology, 18(6): 1035-1041.

Ghoneim, Y.F., Singab, M., Hala, M.A. \& Abd-El-Hai, N.S. 2012. Efficacy of certain insecticides and their mixtures with the tested IGRs against a field strain of the cotton leafworm, Spodoptera littoralis (Boisd.) under laboratory conditions. Australian Journal of Basic and Applied Sciences, 6(6): 300-304.

Gustavo, M.T., Senseman, S.A., Marchesan, E., Camargo, E.R., Jones, T. \& McCauley, G. 2015. Residues of thiamethoxam and chlorantraniliprole in rice grain. Journal of Agricultural and Food Chemistry, 63: 2119-2126.

Hadi, M., Thomas, S., Swevers, L., Kostas, L., Nakagawa, Y. \& Smagghe, G. 2008. Non-steroid ecdysteriod agonist chromafenozide: Gene induction activity, cell proliferation inhibition and larvicidal activity. Pesticide Biochemistry and Physiology, 92: 70-76.

Ignoffo, C.L., Hostetter, D.L., Sikorowski, P.P., Sutter, G. \& Brooks, W.W. 1977. Inactivation of representatives species of entomopathogenic viruses, a bacterium, fungus and protozoan by an ultraviolet light source. Environmental Entomology, 6(3): 411-415.

Lahm, G.P., Stevenson, T.M., Selby, T.P., Freudenberger, J.H., Cordova, D., Flexner, L., Bellin, C.A., Dubas, C.M., Smith, B.K., Hughes, K.A., Hollingshaus, J.G., Clark, C.E. \& Berner, E.A. 2007. Rynaxypyr: A new insecticidal anthranilic diamides that act as a potent and selective ryanodine receptor activator. Bioorganic and Medicinal Chemistry Letters, 17: 6274-6279.
Lessando, M.G., Daiane, C., Obiratanea, S.Q., Raul, N.C. \& Marcelo, C.P. 2015. Impacts of azadirachtin and chlorantraniliprole on the development stages of pirate bug predators (Hemiptera: Anthocoridae) of the tomato pinworm Tuta absoluta (Lepidoptera: Gelechiidae). Florida Entomologist, 98(1): 59-64.

Logan, A.N. 1974. The behaviour of pesticides in plants, in: Proceedings from Environmental and Physiologic Chemodynamics Symposium, Corvallis, pp. 1-6.

Mahdieh, K., Hejazi, M.J. \& Shahzad, I. 2017. Effect of azadirachtin, chlorantraniliprole and some insect growth regulators on vegetable leafminer, Liriomyza sativae (Blanchard) (Diptera: agromyzidae). Journal of Crop Protection, 6(1): 115-123.

Manogem, E.M., Praseeja, C., Shibi, P., Arathi, S. \& Ayisha B. 2015. Effect of chitin synthesis inhibitor, flufenoxuron on haemocytes of Spodoptera mauritia (Boisd.) (Lepidoptera: Noctuidae). International Journal of Plant, Animal and Environmental Sciences, 6(1): 22314490.

Mohd, B.W., Sharma, M. \& Norman, K. 1991. Field evaluation of insecticides and a cultural practice against the bunch moth, Tirathaba rufivena in a mature oil palm plantation. Elaeis, 3(2): 355 362.

Paramananthan, S. 2016. The extent of tropical peat. In: Organic Soils of Malaysia. Malaysian Palm Oil Council, Selangor. pp. 7-8.

Pes, M.P., Melo, A.A., Stacke, R.S., Zanella, R., Perini, C.R., Silva, F.M.A. \& Guedes, J.V.C. 2020. Translocation of chlorantraniliprole and cyantraniliprole applied to corn as seed treatment and foliar spraying to control Spodoptera frugiperda (Lepidoptera: Noctuidae). PLoS ONE, 15(4): e0229151.

Saharul, A.M., Zulkefli, M., Ramle, M., Mohamad, R.S., Su, C.M., Siaw, T.C., Norman, K., Siti, R.A.A. \& Siti, N.A. 2017. Biological agents and insecticides to control bunch moth, Tirathaba rufivena in oil palm estates in Sarawak, Malaysia. Journal of Oil Palm Research, 29(3): 323-332.

Saleh, T.A. \& Abdel-Gawad, R.M. 2018. Electrophoretic and colorimetric pattern of protein and isozyme as reflex to diflubenzuron and chromafenozide treatments of Spodoptera littoralis (Boisd). Journal of Entomology and Zoology Studies, 6(3): 1651-1660.

Saxena, D., Smruti, P. \& Guenther, S. 2010. Fate and effects in soil of Cry proteins from Bacillus thuringiensis: Influence of physicochemical and biological characteristics of soil. The Open Toxicology Journal, 3: 151-171. 
Su, C.M. 2016. Management of Oil Palm Bunch Moth (Tirathaba mundella Walker) In Young Mature Oil Palm Plantation on Peat Soil In Sarawak, Malaysia (Master). Universiti Putra Malaysia.

Su, C.M., Bong, C.F.J. \& Khairulmazmi, A. 2016. Field ablation as cultural control for bunch moth, Tirathaba mundella infestation in young mature oil palm. Journal of Oil Palm Research, 28(4): 463-470.

Su, C.M., King, J.H.P., Kwan, Y.M., Zakry, F.A. \& Ong, K.H. 2020. Economic injury level of oil palm bunch moth, Tirathaba mundella Walker for pest management recommendations in oil palm production. Journal of Oil Palm Research, 33(1): $37-45$.
Temple, J.H., Pommireddy, P.L., Cook, D.R., Marcon, P. \& Leonard, B.R. 2009. Arthropod management susceptibility of selected Lepidopteran pests to rynaxypyr, a novel insecticide. The Journal of Cotton Science, 13: 23-31.

Wood, B.J. \& Ng, K.Y. 1974. Studies on the biology and control of oil palm bunch moth, Tirathaba mundella Walk. (Lepidoptera: Pyralidae). Malaysian Agricultural Journal, 49(3): 310-331. 